\title{
O aplicativo tecnológico Playnatal como mediador da experiência turística e de lazer no destino Natal/RN, Brasil ${ }^{1}$
}

\author{
The technological app Playnatal as a mediator of the tourist and leisure experience in \\ Natal / RN, Brazil
}

\section{La aplicación tecnológica Playnatal como mediadora de la experiencia turística y de ocio en Natal / RN, Brasil}

\author{
Christiano Henrique da Silva Maranhão
}

Pâmela de Medeiros Brandão ${ }^{3}$

Salete Gonçalves ${ }^{4}$

Resumo: Esse artigo busca debater o uso de tecnologias, como possibilidade de mediação das experiências turísticas e de lazer de turistas e residentes no destino Natal/RN, Brasil, a partir do aplicativo PlayNatal. Trata-se de um estudo exploratório-descritivo, de abordagem qualitativa, que usou a técnica análise temática nas avaliações deixadas pelos usuários na página do Facebook e na plataforma de downloads Play store. Conclui-se que o PlayNatal atua como uma inovadora estratégia de negócios, possibilitando a promoção da cidade do $\mathrm{Natal} / \mathrm{RN}$, enquanto destino turístico. Também apresenta possibilidades de contribuir para o processo de mudança comportamental (de turistas e residentes) com vistas na preservação de elementos simbólicos, presentes nas experiências turísticas e de lazer da cidade. Sugere-se para a necessidade de alguns ajustes, como a facilidade do acesso e do contato presencial entre residentes e turistas, nos espaços de turismo e lazer do destino Natal.

Palavras-chave: Experiências turísticas. Lazer. Mediação tecnológica. PlayNatal.

Abstract: This article aims to discuss the use of technologies, as possibility to mediate tourist and leisure experiences of tourists and residents in the destination Natal / RN, Brazil, from the PlayNatal application. This is an exploratory-descriptive study with a qualitative approach, which used the thematic analysis technique in the ratings left by users on the Facebook page and on the Play store download platform. It is concluded that PlayNatal acts as an innovative business strategy, enabling the promotion of city Natal / RN as a tourist destination. It also presents possibilities to contribute to the process of behavioral change (of tourists and residents) aiming at the preservation of symbolic elements, present in the tourist and leisure experiences of the city. It is suggested some adjustments, as the ease of the access and the presential contact between residents and tourists, in the tourism and leisure spaces of the destination Natal, during visitation.

Keywords: Tourist experiences. Leisure. Technological mediation. PlayNatal.

Resumen: Este artículo pretende discutir el uso de las tecnologías, como una posibilidad para mediar en las experiencias turísticas y de ocio de turistas y residentes en el destino

\footnotetext{
Estudo apresentado no evento internacional: OcioGune: o ócio e os novos sistemas digitais, promovido pela Cátedra Ócio e Conhecimento, do Instituto de Estudos de Ócio - Universidade de Deusto, Bilbao (Espanha).

${ }^{2}$ Doutor em Geografia (2017); Mestre em Turismo (2012); Bacharel em Turismo (2009); Universidade Federal do Rio Grande do Norte - UFRN - E-mail: christianomaranhao@gmail.com Orcid: 0000-0003-2938-1989

${ }^{3}$ Doutora em Administração pela Universidade Federal da Bahia, Bacharel e mestre em Turismo pela Universidade Federal do Rio Grande do Norte; Universidade Federal do Rio Grande do Norte -UFRN - E-mail: pamela brandao@yahoo.com.br Orcid: 0000-0001-7488-6666

${ }^{4}$ Doutora em Estudos do Lazer pela Universidade Federal de Minas Gerais; Mestre em Turismo pela Universidade Federal do Rio Grande do Norte (2010); Especialista em Lazer pela Universidade Federal de Minas Gerais (2006); Graduada em Turismo pela Universidade Federal do Rio Grande do Norte (2004); Universidade do Estado do Rio Grande do Norte - UERN - E-mail: salleteg@gmail.com Orcid:0000-0002-3879-6134
} 
Natal / RN, Brasil, desde la aplicación PlayNatal. Este es un estudio exploratorio-descriptivo con un enfoque cualitativo, que utilizó la técnica de análisis temático en las calificaciones dejadas por los usuarios en la página de Facebook y en la plataforma de descarga de Play Store. Se concluye que PlayNatal actúa como una estrategia comercial innovadora que permite la promoción de Natal / RN como destino turístico. También presenta posibilidades para contribuir al proceso de cambio de comportamiento (de turistas y residentes) apuntando a la preservación de elementos simbólicos, presentes en las experiencias turísticas y de ocio de la ciudad. Se sugiere por la necesidad de algunos ajustes, como la facilidad de acceso y el contacto presencial entre residentes y turistas, en los espacios turísticos y de ocio del destino Natal.

Palabras clave: Experiencias turísticas. Ocio. Mediación tecnológica. PlayNatal.

\section{INTRODUÇÃO}

No Brasil, a atividade turística vem se consolidando como um importante vetor de desenvolvimento socioeconômico. Diagnósticos governamentais registram avanços no setor, notoriamente referindo-se à geração de empregos, aos fluxos turísticos domésticos e a entrada de divisas estrangeiras.

No entanto, em que se pese o aumento das visitações turísticas em destinos brasileiros, percebe-se no geral, uma insuficiente interação entre visitantes e residentes. Além disso, na vida cotidiana dos destinos turísticos esse encontro, não raro, é marcado por relações de conflitos e choques culturais que resultam em efeitos danosos para as localidades, a saber: aculturação, xenofobia, prostituição, apropriação indevida de elementos simbólicos e identitários que compõem a diversidade das experiências turísticas e de lazer.

No limiar dessa problemática, testemunha-se um mundo influenciado pela tecnologia digital (Castells, 2010), conjuntura que afeta de forma significativa, e por meio de múltiplas maneiras, a vida social (Gere, 2008; Kirby, 2009).

Revelando a importância da mediação tecnológica, ao considerar o seu potencial para estimular e ampliar a interação social nas experiências turísticas e de lazer, sobretudo, numa sociedade marcada pelo avanço das tecnologias da informação e da comunicação.

Nesse cenário, conforme revelam os estudos de Buhalis e Law (2008), e de Figueiredo e Raposo (2016), a mediação tecnológica vem sendo considerada como um novo paradigma de interação, que tem permitido transformar o turismo tanto em termos de estratégias e práticas de negócios, quanto em termos de novos modos de comportamento e envolvimento do turista e dos residentes.

No entanto, é preciso reconhecer e sublinhar que o uso das tecnologias durante o processo de mediação humana pode fomentar experiências interativas, ao passo que também pode limitá-las, ampliando os problemas já existentes e/ou criando outros.

De todo modo, as tecnologias vêm sendo utilizadas para mediar a interação e a integração do visitante nos destinos turísticos brasileiros, sendo apontada como uma tendência turística nacional em face de seu "potencial para desenvolver do turismo de maneira 'inteligente' por meio da interligação da informação em todas as esferas da localidade proporcionando uma experiência única para o turista e uma qualidade de vida mais elevada ao morador local", conforme citam Mendes Filho et al. (2017: 195).

É a partir desse embasamento que esse artigo discute o uso das tecnologias como recurso mediador das experiências turísticas e de lazer de turistas e residentes no destino Natal/RN, Brasil, a partir do aplicativo PlayNatal (jogo mobile).

Para tanto, apresenta-se as interfaces tecnológicas do aplicativo, avaliando-as na perspectiva dos usuários (1); verifica-se as finalidades e contribuições geradas pelo uso (2); e identifica-se os limites e potencialidades do uso PlayNatal para fomentar as experiências turísticas e de lazer (3). 
Por fim, informa-se que esse artigo se divide em quatro sessões, sendo a primeira composta por essas considerações iniciais, seguida da sessão que apresenta os referenciais teóricos que fundamentam a proposta da pesquisa. Na terceira sessão relata-se os resultados, finalizando com a quarta sessão onde constam as considerações finais.

\section{MATERIAIS E MÉTODOS}

Metodologicamente, conforme Veal (2011), esta pesquisa se caracteriza como exploratório-descritiva. Compreende-se que a meta de coletar informações já prescritas por outros autores, e posteriormente realizar seu devido cruzamento, buscando identificar relações e possíveis desníveis, sinaliza para um perfil exploratório, inerente nas pesquisas científicas que pautam suas questões na temática do turismo, reconhecida como uma área de estudos recente no país. Ainda meditando sobre o caráter exploratório, é possível apontar o uso da pesquisa bibliográfica como uma ferramenta técnica utilizada.

Já sobre o viés descritivo, pontua-se que ele foi utilizado em complemento à perspectiva exploratória. Nota-se que o ato de explorar e a ação de descrever caminham correlacionados para fins interpretativos (Köche, 2013). Somado a isso, observa-se que a própria natureza mutante do turismo solicita descrições, que a posteriori, permitem o confronto de padrões e o esclarecimento de alguma discrepância porventura identificada.

Por esse motivo, aponta-se que o referido artigo pauta-se em um processo interativo de exploração, coleta, descrição e explicação de fatos e dados, promovendo a devida ordenação, de forma a permitir o cruzamento de informações e a devida interpretação.

O estudo ainda consta com uma abordagem qualitativa, devido à necessidade da observação e análise se pautar em características, modo de usos e em subjetividades. Entende-se que a abordagem qualitativa justifica-se, sobretudo, por ser uma forma adequada para entender a natureza de um tipo de conhecimento que está sendo produzido (Veal, 2011).

De forma associada, opta-se pelo estudo de caso, aplicando a técnica da análise temática que "consiste em isolar temas de um texto e extrair suas partes uteis, em conformidade com as questões estudadas, permitindo sua comparação com outros fragmentos selecionados similarmente" (Richardson, 2008:197).

Relata-se que os fragmentos utilizados para a formatação das análises foram coletados por meio das mensagens avaliativas deixadas pelos usuários do PlayNatal em mídia social (Facebook) e na plataforma de downloads Play store (Google play).

De forma complementar, realizou-se uma entrevista semiestruturada, com os idealizadores do aludido aplicativo, a fim de confrontar e lou complementar as informações identificadas no percurso da pesquisa.

\section{MEDIAÇÁO TECNOLÓGICA NAS EXPERIÊNCIAS DE TURISMO E LAZER}

\section{TECNOLOGIA E LAZER: ESTREITANDO O DIÁLOGO}

A tecnologia se faz cada vez mais presente no cotidiano das pessoas, quer seja no ambiente de trabalho, familiar ou de lazer; Influenciando a mudança de alguns hábitos e criando novas demandas. Essa sociedade denominada informacional é geradora de novas formas de produzir e reproduzir conhecimento, e apontam para novos caminhos (Castells, 2003).

Essas transformações também interferem nas experiências de lazer, uma vez que, com o surgimento dos jogos eletrônicos, das mídias sociais, e-books, programas para baixar músicas e filmes/séries on line se é capaz de ter essas experiências, quer seja no tempo de trabalho ou não, aliando-se ao ambiente virtual. Bem como, é possível conhecer museus e diversos espaços culturais com apenas um clique, podendo exercê-lo em qualquer lugar do 
mundo, bastando apenas um notebook, computador, tablet ou smartphone somado ao acesso à internet.

Dentre essas possibilidades, destaca-se os smartphones, que à medida que se integram à experiência de viagem como ferramentas de planejamento, facilitam a busca por informações e estimulam o processo de troca com outros usuários, permitindo realizar atividades sociais a qualquer momento da viagem, abrindo "um leque" de novas oportunidades para o viajante conhecer o destino a partir de outro ângulo (Saari \& Yoo \& Tussyadiah, 2008; Tussyadiah \& Fesenmaier, 2009; Wang \& Park \& Fesenmaier, 2011).

Nota-se que paralelo a facilidade de planejar a viagem, proporcionando flexibilidade e espontaneidade, os smartphones também desempenham o papel de ferramentas de mediação turística durante a viagem, construindo um "olhar guiado" representativo (Wang \& Park \& Fesenmaier, 2012) que pode dar forma e direcionar às experiências dos viajantes.

Observa-se que os guias móveis, por exemplo, aumentam a consciência temporal e espacial do local, enriquecendo a experiência e influenciando em maior medida as decisões e movimentos dos turistas.

Ampliando essa discussão e partindo do princípio que o turismo é uma das possibilidades do lazer, o mesmo também vem fazendo uso dessas tecnologias para atrair novos consumidores e expandir novos mercados.

Nesse sentido, os turistas vêm acessando cada vez mais a internet a procura de informações sobre destinos e produtos de viagem. Buscando meios que possam dar maior suporte às suas escolhas, quer seja através das avaliações de determinados sites, ou através de experiências virtuais que remetam a realidade, reduzindo os riscos, já que se tratam de produtos intangíveis (Hassan, 2011).

Como se pode observar, a internet permite aos turistas e residentes acesso a informações que possibilitam um maior grau de autonomia nas escolhas dos espaços, equipamentos e serviços a serem escolhidos. Além disso, é possível realizar reservas e efetuar pagamentos, otimizando o tempo e evitando algum problema que venha a surgir por formas convencionais de compra. Logo, permite maior rapidez e transparência para comparar destinos, pacotes turísticos, hospedagem, restauração, serviços e espaços de lazer, bem como sobre os preços e a disponibilidade dos mesmos, facilitando a vida desses sujeitos.

Sendo assim, percebe-se que cada vez mais as pessoas utilizam sites comerciais e não comerciais da internet para o planejar, pesquisar, comparar, reservar, comprar e alterar os seus produtos e serviços de lazer e turismo, otimizando a vivência de suas experiências. Essa prática pode auxiliar na escolha do que fazer, provocando o interesse em conhecer novos espaços, equipamentos e serviços, apresentando novas possibilidades e interferindo na vida atual das pessoas. E esta prática não limita-se aos visitantes, ou seja, também engloba os residentes.

Diante desse cenário, constata-se que no ambiente virtual mudam-se os espaços e tempos, criando novos níveis e tipos de interações. A tecnologia faz com que se torne cada vez mais permeável a separação do espaço e tempo, onde essas categorias acabam assumindo outra lógica. Essas mudanças são reflexos das inúmeras mudanças vivenciadas na contemporaneidade, dentre elas a compressão espaço-tempo (Harvey, 2010) e a destemporalização do espaço social, ou seja, "o tempo já não estrutura o espaço. [...] o que conta é exatamente a habilidade de se mover e não ficar parado" (Bauman, 1998: 113), tornando assim, os limites entre os campos complexos e difusos.

Nesse sentido, surge uma nova perspectiva de lazer que vislumbra seu contexto histórico, político, social e cultural, tendo como referência Gomes $(2011 ; 2014)$. Segundo a autora é importante "[...] reconhecer que o lazer é uma prática social de vida cotidiana que precisa ser situada em cada tempo/espaço social, e que, justamente por isso, integra diferentes culturas" (Gomes, 2014:8)

Dessa forma, pensar o lazer na contemporaneidade é também pensá-lo no campo da virtualidade, no cyberespaço, na relação entre mundo virtual e mundo atual. Tornando-se 
frágil a separação entre tempo de trabalho e de não-trabalho, com o uso da tecnologia na vida cotidiana essa distinção deve ser repensada.

Frente a esse cenário, já não cabe à dicotomia entre trabalho-lazer, ócio-negócio, virtual-atual, ou qualquer outro tipo de oposições, mas deve-se compreender o lazer como uma prática social complexa e que tem suas particularidades em cada contexto local e temporal, devendo ser situado historicamente.

Gomes (2011:17) provoca outras reflexões ao compreender o lazer "[...] como uma necessidade humana e como dimensão da cultura caracterizada pela vivência lúdica de manifestações culturais no tempo/espaço social". Logo, entendendo-o como necessidade torna-se algo imprescindível ao homem, e enquanto dimensão da cultura entende-se que o mesmo é construído socialmente e inserido em todo o seu contexto de vida.

Em seu conceito pode-se destacar ainda três elementos que se inter-relacionam e são fundamentais para o entendimento do lazer: a ludicidade, as manifestações culturais e o tempo/espaço social.

O primeiro elemento refere-se à ludicidade, sendo esta entendida como uma expressão humana, onde o sujeito criador se torna capaz de dar significado à sua existência, ressignificar e transformar o mundo (Debortoli, 2002). Podendo ser manifestado de diversas formas, já que é linguagem e capaz de promover diversos tipos de emoções.

Sobre as manifestações culturais podem ser consideradas uma série de vivências e práticas sociais que podem suprir a necessidade de fruição do lazer e variam e acordo com cada contexto histórico. Pode-se destacar o aspecto virtual, dentre tantas outras. Corroborando com essa perspectiva:

Obviamente, as variadas manifestações culturais são possíveis de transformação e são influenciadas por distintas sociedades e culturas, especialmente em um mundo globalizado. Por isto, o lazer não se refere apenas as práticas chamadas tradicionais ou folclóricas, mas também a todo tipo de prática social geralmente considerada como moderna e emergente. Entre elas, por exemplo, podem ser citadas as experiências ligadas à virtualidade, os novos gostos musicais, estilos de festas ou determinadas atividades que para una pessoa de outra geração ou de outra cultura podem não ser compreendidos'. (Gomes, 2014b : 364-365).

Outro aspecto interesante sobre o lazer, apontado por Cuenca Cabeza (2014: 28) diz que: "[...] las experiencias de ocio afectan a la persona en su totalidad y también se interrelacionan con el entorno local y global'.

Destarte, com o auxílio da tecnologia no campo do lazer e turismo, acredita-se que essas experiências podem ser otimizadas, e contribuir cada vez mais com o desenvolvimento pessoal, local e global, na medida em que gera conhecimento que pode ser difundido entre os seus usuários e a sociedade. Essas melhorias podem ser potencialidades através do processo da mediação tecnológica, tema que será abordado na secção a seguir.

\section{MEDIAÇÃO TECNOLÓGICA NO CAMPO DO LAZER E TURISMO}

Para se pensar na mediação tecnológica no campo do lazer e turismo, deve-se primeiramente considerar que "[...] el ocio, en cuanto vivencia solidaria, representa un potencial de desarrollo de gran trascendencia para una comunidad". (Cuenca Cabeza, 2014 : 33-34). Ou seja, pensar esse campo enquanto possibilidade de transcendência, de mudança do sujeito e da sociedade onde vive.

Nesse sentido, o uso da tecnologia no campo do lazer pode contribuir com o desenvolvimento social e com o processo emancipatório dos sujeitos, e dependendo do seu uso e mediação, pode fortalecer a manutenção do status quo. Dessa forma, deve-se constatar que, se por um lado a mediação tecnológica pode promover maior interatividade 
entre os sujeitos (turistas e residentes), gerar mais informação, dar maior acessibilidade, maior comodidade, baixo custo ou custo zero para o usuário, sendo mais benéfica ao meio ambiente. Por outro lado, pode limitar-se e mostrar só uma parte da realidade, atendendo a interesses de alguns, com destaque aqui para o expressivo papel político da mediação.

Ressalta-se que existem diferenças de uso da tecnologia, conforme aponta Dowbor (2001), e que as tecnologias não vão mudar o sistema, mas aliadas a outras formas de conhecimento, outros canais de informação podem tornar a experiência mais prazerosa, com maiores níveis de desenvolvimento e aprendizagem. Sendo assim, ao se pensar em uma vivência de lazer mediada por tecnologias, deve-se pensar também na presença de outros agentes sociais que podem auxiliar nesse processo. Corroborando com essa perspectiva, se faz necessário pontuar que:

[...] as tecnologias são produtos da ação humana, historicamente construídos, expressando relações sociais das quais dependem, mas que também são influenciadas por eles. Os produtos e processos tecnológicos são considerados artefatos sociais e culturais, que carregam consigo relações de poder, intenções e interesses diversos. (Oliveira, 2001:101102).

Percebe-se que sempre há um interesse nesse processo de mediação, por isso deve haver uma interação entre quem media e quem é mediado, apresentando-se como uma possibilidade dentre as mais diversas, revelando um caminho que deve ser agregado a outros meios para atender com maior precisão o seu fim. Por essa razão:

[...] a mediação tecnológica está sendo entendida como um processo complexo, constituído de instrumentos e signos, construídos intencionalmente pelos homens, com o propósito de estimular e ampliar relação dos sujeitos com o conhecimento, com o mundo e com os outros sujeitos. A mediação tecnológica passa a ser também pedagógica e ontológica na medida em que se situa como instrumento e como signo nos processos internos de aprendizagem e apropriação de conhecimento. Ela não pode ser vista como fim em si mesmo, mas como um prolongamento da relação do sujeito com a realidade por intermédio dos processos de apreensão que ele produz. (Thiesen, 2011:03).

Destaca-se que a mediação tecnológica vem apresentando experiências bem sucedidas em diversos países, de maneira eficaz e com baixo custo de implantação na área da educação (Thiesen, 2011), e por isso, acredita-se que não se deve diferir no campo do lazer e turismo. Entende-se que a utilização destes recursos tecnológicos possibilita o acesso a um expressivo número de informações, incentiva a integração entre os sujeitos, contribui com o imaginário dos usuários, com a descoberta de novos espaços, de experiências interativas e lúdicas, porém é inegável que isso não substituí a experiência física e presencial, antes complementa-a.

Nesse sentido, percebe-se que um dos grandes desafios da mediação tecnológica no âmbito do lazer e turismo é de superar o uso do recurso como mero instrumento, e assumir que o mesmo pode nortear a experiência, tendo um viés político, e mostrar que essa é apenas uma das várias possibilidades existentes, podendo superar a visão de puro consumismo e/ou de mero entretenimento, mas também de desenvolvimento social.

\section{RESULTADOS E DISCUSSÕES}

\section{O PLAYNATAL E AS INTERFACES TECNOLÓGICAS}

Reflexo do cenário mundial e contemporâneo, onde a virtualidade assume um papel relevante no contexto social, a ideia original do PlayNatal surgiu em agosto de 2015, a partir 
da experiência pessoal de dois natalenses e um fortalezense, respectivamente, Felipe Farias (Publicitário), Eduardo Leite (Engenheiro Químico) e Stefano Farias (Engenheiro de Produção), que ao morarem em outras cidades e países, perceberam que a cidade do Natal necessitava ampliar suas ações de divulgação, promoção e marketing, pensando por meio do viés da atividade do turismo. Os idealizadores do PlayNatal, expuseram durante a entrevista, que quando se pensa no cenário internacional, a "cidade do Natal sequer é conhecida [...] sendo sempre São Paulo e Rio de Janeiro os únicos pontos de referência do Brasil' (Dados da pesquisa, 2018).

Face ao exposto, os idealizadores do aplicativo decidiram atuar nesta conjuntura, enfatizando o orgulho de serem natalenses e/ou moradores da cidade, e paralelo a isso, contribuindo para a divulgação da cidade do Natal para o mundo, atuando diretamente no melhoramento promocional de seu potencial turístico. "O PlayNatal nasceu para mostrar Natal de uma forma diferente" (Dados da pesquisa, 2018).

Fundamentado nessas percepções, o PlayNatal foi lançado oficialmente ao público no dia 8 de março 2017. De forma técnica, o PlayNatal é um jogo 2D para mobile, criado na base de game infinity running, e desenvolvido em plataforma Unity, disponível gratuitamente na AppStore e GooglePlay. O objetivo central do jogo é apresentar e/ou fazer conhecer os principais pontos turísticos da cidade, além de curiosidades, gírias e dicas de conscientização e sustentabilidade, com isso, motivar fluxos de visitantes (domésticos e internacionais).

O PlayNatal conta com cinco fases, onde cada uma delas está ambientada em um ponto turístico diferente da cidade, a saber: Praia de Ponta Negra, Forte dos Reis Magos e Via costeira. Além destes três pontos turísticos natalenses, o jogo ainda apresenta os cenários da Praia de Pipa, localizada no município de Tibau do sul, e do Cajueiro, situado no município de Parnamirim.

Cabe esclarecer, conforme os idealizadores, que os pontos turísticos foram selecionados a partir de uma pesquisa realizada com potenciais usuários do jogo, os quais sinalizaram estes lugares da cidade do Natal, como os principais espaços que apresentam identidade para a atividade turística local.

Sabendo disso, informa-se que em face ao processo de aprimoramento do jogo, outros pontos turísticos já estão em processo de desenvolvimento visando às próximas atualizações. Adianta-se, de forma exclusiva, que as próximas fases do jogo, abordarão o bairro boêmio da Ribeira e a temática das festas juninas (São João), realizadas todo no mês de junho.

Cabe destacar que o PlayNatal apresenta como personagem principal o "Juca", inspirado nos surfistas que diariamente encontram-se na praia de Ponta Negra. Destarte, o personagem percorre, com a ajuda de comandos simples, os principais pontos turísticos da cidade, coletando pontos chamados de CajuCoins, elemento lúdico do jogo que faz alusão e é inspirado em uma das principais frutas cultivadas na cidade, o caju.

Alinhado com este cenário lúdico, informa-se que a posse de uma quantidade determinada de CajuCoins, torna-se possível à troca dos pontos por vouchers vinculados às ofertas exclusivas, por meio de parcerias estabelecidas com alguns dos principais serviços relacionados ao turismo da cidade. Em conformidade com a fala dos idealizadores, 0 PlayNatal apresenta atualmente cerca de 15 parceiros entre anunciantes e vouchers. Este portfólio de serviços engloba uma diversidade de opões, abrangendo de camiseterias com frases típicas da cidade, hamburguerias, loja de pescados, lojas de açaí, shoppings e hotéis.

Quando se pondera sobre estas parcerias, e conforme os idealizadores do aplicativo, o grande obstáculo é fazer com que a marca PlayNatal possa ser reconhecida, facilitando com isso, uma maior receptividade para com novos parceiros. "Aos poucos estamos construindo nossos números para facilitar essa interação e convencimento que o PlayNatal é uma mídia que vale a pena ser investida" (Dados da pesquisa, 2018). 
Falando ainda sobre as interfaces tecnológicas do PlayNatal, o jogo também disponibiliza a possibilidade de ganhar "novas vidas", a partir da coleta de outro símbolo que representa a cultura gastronômica da Cidade do Natal, o fruto chamado de Jerimum.

Somado a isto, na passagem de uma fase para outra, surgem outros recursos interativos como por exemplo: "Você Sabia?" que apresenta curiosidades e informativos sobre o cenário onde o jogo acontece, desde a época da Segunda Guerra Mundial (19391945), momento em que a cidade serviu de base para os soldados americanos, até os dias contemporâneos. Relata-se que todas estas informações são transmitidas pelo jogo ao som de trilhas sonoras de bandas locais, de variados estilos.

De acordo com a entrevista realizada com os idealizadores, o aplicativo com apenas dois dias de funcionamento já contava com 300 downloads. Atualmente, o PlayNatal acabou de completar 3 anos desde que foi lançado e já consta com mais de 1900 jogadores, os quais atingiram a marca de mais de 80 mil fases jogadas e mais de 300 vouchers trocados. O download do jogo está disponível mundialmente, entretanto, o foco inicial da divulgação está centralizada na cidade do Natal e no estado do Rio Grande do Norte.

Os idealizadores defendem que os esforços de divulgação do aplicativo devem iniciar pelos potiguares de forma geral, para na sequência atingir turistas e visitantes. Por essa razão, em torno de $90 \%$ dos jogadores cadastrados no aplicativo são potiguares. Mas já existe um esforço com vistas em uma maior divulgação a nível regional, ampliando o escopo do jogo, e paralelamente do sistema de funcionamento de vouchers. Busca-se a priori, se consolidar entre os moradores da cidade, para logo após, alcançar os visitantes e turistas potenciais.

O jogo chama atenção por onde passa. Em abril de 2017, quase 5 mil pessoas

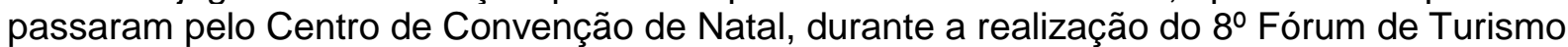
de Natal e da 3a $3^{-}$Feira dos Municípios e Produtos Turísticos do RN (Femptur). O público, basicamente formado por empresários do setor, estudantes e pesquisadores do turismo, além de trabalhadores vinculados ao turismo de lazer e de eventos, puderam visitar o stand do jogo e interagir com os idealizadores, fazendo questões e esclarecendo algumas dúvidas. O PlayNatal também esteve presente no SAGA ${ }^{\mathrm{ii}}$, maior feira de games do estado do Rio grande do Norte.

Por todo o exposto, é pertinente dizer que o PlayNatal configura-se em uma iniciativa inovadora, relacionada com o turismo de lazer, que proporciona diversão, ludicidade e interatividade entre seus usuários (turistas e residentes), e simultaneamente, divulga as particularidades locais e os pontos turísticos da cidade do Natal, elementos que compõem a identidade da capital potiguar.

\section{FINALIDADES E CONTRIBUIÇÕES FOMENTADAS PELO USO DO PLAYNATAL}

Meditando sobre as finalidades e contribuições promovidas pelo uso do jogo, informa-se que as análises estão embasadas no cruzamento de informações coletadas por meio da avaliação feita pelos usuários, e divulgadas nas redes sociais (Facebook) e nas resenhas do Playstore, assim como no discurso dos idealizadores, coletado por meio da entrevista.

Verificando as avaliações do Facebook é possível apontar que, mesmo na ausência de posicionamentos mais detalhados dos usuários, dentre as 124 avaliações, 119 delas, ou seja, 95,96\% dos usuários avaliam o jogo com 05 estrelas (pontuação máxima). Ainda seguindo os critérios de avaliações da referida rede social, é permitido informar que somente 01 usuário avaliou o jogo com 02 estrelas, inexistindo avaliações de 01 estrela, ou seja, de pontuação mínima.

Contudo, quando a análise direciona-se para as resenhas publicadas no Playstore, esta fornece mais elementos que configuram uma base mais detalhada de subsídios para exposição. Assim, de um total de 40 resenhas postadas, 20 delas $(50 \%)$ contribuíram para com as análises deste artigo. Justifica-se que as resenhas selecionadas, apresentam conteúdos que demonstram alinhamento com a proposta do artigo. 
Destarte, quando se pensa nas finalidades presentes no jogo PlayNatal, é permitido destacar o intuito de fomentar de ideias de pertencimento, identidade e orgulho dos natalenses para com a cidade. Desde a concepção do projeto, já existia a intenção de despertar no natalenses, características que remetem as peculiaridades do local vivido. Ratificando esta fala, é possível destacar no Quadro 1, algumas das expressões em negrito, que estão presentes nas avaliações dos usuários, publicadas nos espaços disponíveis.

Quadro 1: Expressões que remetem à identidade, pertencimento e orgulho da cidade.

"O jogo é 10 mostra os pontos da minha amada cidade!"

"Ótimo, muito bom! Um joguinho representando nosso estado".

"Nem joguei, mas só de valorizar a minha cidade está merecendo".

"Muito bom para esta cidade maravilhosa".

"Ótimo jogo da minha cidade".

"Representa bem nossa cidade! Jogabilidade agradável e viciante".

"Excelente jogo e iniciativa para a cidade. Parabéns!".

Fonte: Dados da pesquisa, 2018.

Assim, com base nos fragmentos em destaque, percebe-se que o jogo alcançou a finalidade em motivar e despertar a curiosidade, contribuindo para a construção e o aprimoramento da identidade do lugar e de sua valorização por parte dos moradores. Somado a isso, reconhece-se a ideia de pertencimento e orgulho de ser residente da cidade do Natal. É com base na valorização e relação com a cidade, que se busca gerar ações coletivas e cidadãs para com os temas que tratam da sustentabilidade, civilidade, valorização cultural dentre outros.

Outra finalidade que se pode destacar, diz respeito ao impulso necessário que o setor de games necessitava na cidade, visto que trata-se de uma tendência mundial. Os idealizadores apontaram que o jogo também tem a meta de impulsionar e colaborar para a área de games, que ainda é pouco explorada no cenário local. Diante disso, o PlayNatal começou a se inserir no mercado de games e com isso, ser reconhecido e premiado no cenário nacional. Conforme os idealizadores: "No final de 2016, ficamos no Top 3 Brasil num concurso realizado pela Prefeitura de São Paulo para os jogos mais criativos do país, sendo o único representante do nordeste brasileiro na final" (Dados da pesquisa, 2018).

Complementar a esta informação, identifica-se que os usuários expuseram em suas análises, comentários que pontuam algumas contribuições do aplicativo, enquanto ferramenta tecnológica e promocional. De acordo com o Quadro 2, é possível identificar as expressões em negrito, que embasam esta fala.

Quadro 2: O PlayNatal enquanto ferramenta tecnológica e serviços associados.

"O jogo é incrível, a ideia fantástica, a aparência também está de parabéns. Conheci o jogo ontem no SAGA, amei. Parabéns a todos os responsáveis";

"Jogo muito bem produzido e a ideia de trocar os pontos por ofertas é ótima";

"Ótima ideia! Vai se espalhar pelo Brasil, certeza!".

Fonte: Dados da pesquisa, 2018.

Ainda na visão dos idealizadores, o PlayNatal apresenta avanços e impactos importantes, relacionados ao ambiente dos games, com repercussões diretas no setor do turismo local, destacados na fala:

O impacto no turismo através de um novo conceito que já está presente em outros setores chamado de Gamefication e Tourism Gamefication, o qual já é usado em outras partes do mundo para melhorar a experiência do turista nos locais visitados, instigando a interatividade e aprendizado sobre a cultura local (Dados da pesquisa, 2018). 
Paralelo a isso, os idealizadores ainda apontam como contribuição do PlayNatal, a forma como as fases do jogo foram pensadas e construídas, priorizando informações, curiosidades e fatos turísticos e históricos sobre a cidade, destacando as gírias locais e campanhas de conscientização. Outra contribuição importante mencionada pelos idealizadores, faz referência à dinamização da economia local. Segundo eles:

\begin{abstract}
Desde o primeiro rascunho o PlayNatal sempre se teve o intuito de sair do ambiente online, e não ser apenas mais um game de passatempo, mas ter uma experiência off-line que impactasse no mundo real. Dessa forma o PlayNatal vem contribuindo com estabelecimentos locais através da publicidade interna no jogo, com banners e também dos vouchers promocionais. Assim as marcas locais tem a possibilidade de usar essa mídia alternativa e inovadora para divulgação e atrair novos clientes com os vouchers (Dados da pesquisa, 2018).
\end{abstract}

Deste modo, entende-se que o jogo acaba contribuindo para a divulgação de parceiros, fazendo uso de uma mídia inovadora e de rápida circulação, por meio de imagens e propagandas inseridas dentro da própria dinâmica do jogo. O que evidencia também o viés econômico que gera base importante para o fomento e aceite do jogo pelo trade turístico da cidade do Natal. O jogo acaba contribuindo e motivando também, conforme relato dos idealizadores, para a visitação de residentes e turistas aos pontos turísticos apresentados e ilustrados nas fases do jogo.

Já recebemos relatos de jogadores que não conheciam o Forte dos Reis Magos e foram visitar justamente pela curiosidade que o jogo proporcionou. São depoimentos como esse que mostram a importância do nosso trabalho (Dados da pesquisa, 2018).

Ainda conforme a fala dos usuários, o jogo PlayNatal é visto como um importante mediador e motivador de interesse, quando se pensa na visitação dos moradores e turistas aos pontos turísticos de Natal/RN e de seus principais espaços públicos, divulgados nas fases do jogo. Verifica-se nas falas dos usuários, a seguintes sentenças, expostas no Quadro 3:

Quadro 3: O PlayNatal enquanto mediador de interesse da cidade e de seus espaços públicos e turísticos.

"Melhor jogo para crianças! Meu sobrinho agora tá doido pra conhecer o forte dos reis magos!". "Foi bom aprender um pouco sobre Natal. Poderia ter fases no bairro de Felipe Camarão". "Muito bom! Adorei conhecer melhor a bela Natal!"

Fonte: Dados da pesquisa, 2018.

Desse modo, observa-se que o aplicativo PlayNatal acaba assumindo a função de expositor, de parte das experiências, que podem ser vivenciadas na cidade do Natal, assim como de possibilidade de divulgação de outros lugares que gera identidade para os moradores da cidade, mas que ainda não fazem parte do roteiro turístico.

\title{
LIMITES E POTENCIALIDADES DO USO PLAYNATAL PARA FOMENTAR AS EXPERIÊNCIAS TURÍSTICAS E DE LAZER
}

Já quando se medita sobre os possíveis limites e principais potencialidades apresentadas pelo aplicativo PlayNatal, é permitido expor como uma primeira potencialidade, a interatividade e motivação pela vivência e experiência do real, esta benesse pode ser identificada na opinião dos idealizadores quando falam na, 
Interação de trazer o jogador para experiência na vida real, seja para visitar um ponto turístico ou trocar seu voucher promocional. Mas que começa através dessa interface inovadora e lúdica do game em si, que pode ser jogado de qualquer lugar e por pessoas de qualquer idade (Dados da pesquisa, 2018).

Outra potencialidade que se associa ao jogo é a possibilidade de inserção, na política de (vouchers) ofertada pelo aplicativo, de descontos ou gratuidade no acesso aos Museus, Igrejas históricas, Parques, Cinemas, Parques aquáticos e participação de passeios culturais da cidade do Natal. Atualmente os descontos são restritos a alguns pontos da cidade e algumas vivências. Contudo já se vislumbra um maior alcance e abrangência com relação ao acesso dos usuários, em espaços e eventos ligados ao lazer e entretenimento em Natal/RN.

Essa possibilidade existe e já está sendo trabalhada com alguns parceiros. Estamos fechando com parque aquático, cinema e esportes radicais para não ter apenas produtos, mas também serviços como esses que proporcionem uma experiência turística aos usuários (Dados da pesquisa, 2018).

Outra potencialidade identificada é a opção de lazer, entretenimento e ócio criativo, as quais estão em negrito, nas avaliações dos usuários, expostas no Quadro 4.

Quadro 4: jogo visto como uma opção de lazer, entretenimento e ócio criativo.

"Dá para conhecer a cidade ao mesmo tempo que joga e se diverte";

"Jogo animado! Indicado para galera geral de todas as idades";

"Muito legal pra quem procura um passatempo divertido".

Fonte: Dados da pesquisa, 2018.

Já quando se pensa nas limitações presentes no PlayNatal e nas suas condições de melhoramento, é permitido destacar, da fala dos idealizadores, o seguinte trecho: "Por ser uma ideia inovadora sempre existe alguma rejeição inicial, mas estamos quebrando os paradigmas e inovando" (Dados da pesquisa, 2018).

Entende-se que por ser um ambiente novo para cidade, o trade turístico teve dificuldade de creditar confiança a essa empreitada desafiadora. Ao mesmo tempo em que O PlayNatal pode ser visto como uma inovação mercadológica, também pode ser entendido como um risco, em tempos de crise, que por isso solicitava cautela.

Já com base nas avaliações dos usuários, surgem outros limites e algumas sugestões de melhoramento do jogo. Com destaque para a utilização de novos e/ou outros espaços turísticos ou não, característicos da cidade do Natal, assim como o debate sobre a diversidade de gênero e o empoderamento feminino, temas presentes nos principais debate na atualidade.

Assim, expondo as principais proposições e opiniões de melhoramento do jogo, ampliando o alcance positivo já ofertado pelo game, têm-se os seguintes fragmentos, apresentados pelos usuários, expostos no Quadro 5.

Quadro 5: Proposições e opiniões de melhoramento e ampliação do jogo.

\begin{tabular}{l} 
"Jogo excelente! Aguardando versão com itens que promovam a diversidade de gênero e o \\
protagonismo da mulher potiguar"; \\
\hline "Seria bom umas fases como Alecrim, Cidade Alta, Ribeira, Bosque dos Namorados \\
(parque das dunas), Arenas das Dunas, e a variação de outras bandas potiguares como \\
Rastafeeling que tem uma linda música Cidade do Sol, Plutão Já Foi Planeta, Felipe Toca, \\
Alamoana, Camarones. Colocar mais histórias da cidade. Mais deixo aqui meus parabéns pela \\
iniciativa e de um belo trabalho, espero que ganhe mais oportunidades e apoios"; \\
\hline "Seria bom uma fase de baia formosa".
\end{tabular}




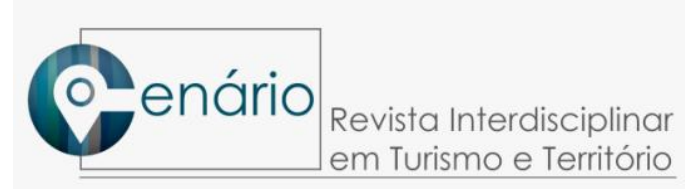

Fonte: Dados da pesquisa, 2018.

Já quando se pensa na avaliação do PlayNatal, com vistas no melhoramento do jogo, os idealizadores expuseram que está sendo positiva nesses dois meses, desde lançamento. Considerando tanto os números alcançados como também a satisfação dos jogadores com o conceito e funcionamento do jogo.

Podemos citar as centenas de avaliações no Google Play, AppStore e Facebook onde temos média de 04 a 05 estrelas. Também tivemos vários convites para eventos, entrevistas, reportagens, concursos e até artigos científicos. Esses foram só os primeiros meses para percebermos que o PlayNatal está na direção certa. Estamos trabalhando para lançar fases e personagens novos bem como dar mais opções de promoções para os jogadores. Em breve serão lançadas as atualizações com mais novidades (Dados da pesquisa, 2018).

Assim, embora o PlayNatal seja uma experiência interativa recente, os resultados já alcançados e as avalições realizadas pelos seus usuários ratificam o seu caráter inovador e estratégico, tanto em termos de promoção e divulgação da cidade de Natal, quanto em termos de estímulo ao desenvolvimento de relação triangular turistas-residentes-território.

\section{CONSIDERAÇÕES FINAIS}

O uso da tecnologia no âmbito do lazer e do turismo, possibilita no estudo em questão, um acesso significativo de informações do destino Natal para residentes e turistas. Entende-se que embora tratem-se predominantemente de atrativos turísticos, os mesmos são primeiramente, espaços da cidade que remetem a sua identidade e história.

Dessa forma, o aplicativo PlayNatal torna-se um incentivador à integração da comunidade local e dos turistas com alguns dos elementos de composição da identidade da cidade. Os usuários do aplicativo poderão planejar suas visitas aos espaços de lazer a partir das informações coletadas no game. Bem como, torna-se um incentivador desses espaços de lazer, por meio de informações e curiosidades sobre a cidade.

Como resultado tem-se que, embora o aplicativo busque a divulgação turística do destino Natal/RN, contribuindo para a promoção dos atrativos e equipamentos turísticos, curiosidades e dicas cidadãs; e consequentemente com o retorno econômico dos parceiros, evidenciado pelos descontos ofertados em serviços turísticos; ele ainda apresenta possibilidades efetivas de fomento de experiências turísticas e de lazer, partilhadas por turistas e residentes, que acabam assumindo funções diferenciadas.

A opção de iniciar pelos residentes, permite que os mesmos vivenciem o cotidiano da cidade que residem, e capacita-os como agentes disseminadores das potencialidades do destino. A identidade, o pertencimento, a apropriação do espaço público, a difusão de informações, as experiências, a manifestação da ludicidade e a educação para o lazer são algumas das possíveis contribuições apontadas pelos usuários (turistas e residentes), para além do enfoque econômico e divulgação do destino.

Avalia-se que existem efetivas potencialidades para experiências turísticas e de lazer tecnologicamente mediadas, devendo atentar para a necessidade de alguns ajustes, a fim de ampliar as vantagens e oportunidades presentes no game, fomentando por fim, acessos e contatos presenciais entre turistas e residentes, diante da visitação dos inúmeros espaços de turismo e lazer do destino Natal. Acredita-se ainda que uma maior divulgação do próprio aplicativo nas mídias sociais fará com que um maior número de pessoas (turistas e residentes) possa ter maior acesso a esse canal.

Como sugestão de melhoramento, diante de uma possível atualização do aplicativo, aponta-se a possibilidade de inserção de outros elementos, tipicamente natalenses, situados 
no litoral norte da cidade, como por exemplo: o cajueiro e mercado da Redinha, o prato tradicional da Ginga com tapioca, O roteiro cultural da cidade alta (Igrejas, Museus, Marco Zero da cidade), Rio Potengi, Ponte de Igapó, Parque das Dunas, Buggys dentre outros.

Outra colaboração que pode acrescentar ao escopo do aplicativo diz respeito à inserção de informações a respeito do enfrentamento à exploração sexual de crianças e adolescentes no contexto do turismo, no estado do Rio grande do Norte, divulgando os canais de denúncia e a legislação que pune o crime de exploração sexual.

As informações podiam aparecer como lembretes ou placas de sinalização, ou até mesmo nas curiosidades do quadro "Você sabia?". Este posicionamento estaria alinhado ao pioneirismo do estado na luta contra a exploração de crianças e adolescentes no turismo, que possibilitou de forma inédita em toda América latina, por meio da ONG RESPOSTA, a criação do primeiro código de conduta contra exploração sexual de crianças e adolescentes.

Conclui-se, em síntese, que o PlayNatal conforma-se como uma inovadora estratégia e prática de negócios, na medida em que permite a promoção e divulgação da cidade de Natal enquanto um destino turístico, bem como de seus empreendimentos e equipamentos de turismo e lazer. Além disso, o jogo apresenta contundentes possibilidades de contribuir, via mediação tecnológica, no processo de mudanças comportamentais e para uma devida apropriação dos elementos simbólicos e identitários que compõe a diversidade das experiências turísticas e de lazer dessa cidade, tanto para residentes como para turistas.

\section{REFERÊNCIAS}

Bauman, Z. (1998). O mal-estar da pós-modernidade. Rio de Janeiro, Brasil: Zahar.

Buhalis, D., \& Law, R. (2008). Progress in information technology and tourism management: 20 years on and 10 years after the Internet - The state of eTourism research. Tourism Management, 29 (4), 609-623.

Castells, M. (2003). A sociedade em rede. A era da informação: economia, sociedade e cultura. v.1, 9ª ed. São Paulo, Brasil: Paz e Terra.

Castells, M. (2010). The Information Age: Economy, Society and Culture. The Rise of the Network Society, Vol 1. Oxford: Wiley-Blackwell.

Cuenca Cabeza, M. (2014). Aproximación al ocio valioso. Revista Brasileira de Estudos do Lazer, 1 (1). Recuperado de: https://seer.lcc.ufmg.br/index.php/rbel.

Dowbor, L. (2001). Tecnologias do conhecimento: os desafios da educação. Rio de Janeiro, Brasil: Vozes.

Figueiredo, C., \& Raposo, R. (2016). O ciclo da experiência turística e a tourist user experience à luz da convergência e dos novos paradigmas de interação. SOPCOM: Associação Portuguesa de Ciências da Comunicação. 409-416.

Gere, C. (2008). Digital Culture. London: Reaktion Books.

Gomes, C. L. (2011). Estudos do lazer e geopolítica do conhecimento. Revista Licere, 14 (3). Recuperado de: http://www.anima.eefd.ufri.br/licere/pdf/licereV14N03 ar1.pdf.

Gomes, C. L. (2014). Lazer: necessidade humana e dimensão da cultura. Revista Brasileira de Estudos do Lazer, 1 (1). Recuperado de: https://seer.lcc.ufmg.br/index.php/rbel. 


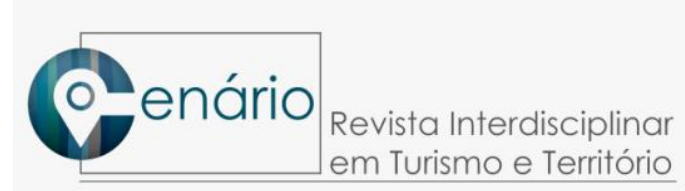

Harvey, D. (2010). A condição pós-moderna: uma pesquisa sobre as origens da mudança cultural. 20aㅡ ed. São Paulo, Brasil: Loyola.

Hassan, H. (2011). Tecnologias de Informação e Turismo: e-tourism. Dissertação de Mestrado em Lazer, Patrimônio e Desenvolvimento. Faculdade de Letras da Universidade de Coimbra. Coimbra, Portugal.

Kirby, A. (2009). Digimodernism. New York: Continuum

Mendes Filho, L. et al. (2017). Aplicativos Móveis e Turismo: Um Estudo Quantitativo Aplicando a Teoria do Comportamento Planejado. Rosa dos Ventos -Turismo e Hospitalidade, 9(2). Recuperado de: http://www.ucs.br/etc/revistas/index.php/rosadosventos/article/view/4787/pdf .

Oliveira, M. R. N. S. (2001). Do mito da tecnologia ao paradigma tecnológico; a mediação tecnológica nas práticas didático-pedagógicas. Revista Brasileira de Educação, 18. Recuperado de: http://www.scielo.br/pdf/rbedu/n18/n18a09.

Richardson, R. J. et al. (2008). Pesquisa social: métodos e técnicas. 7. ed. São Paulo: Atlas.

Rimkus, C. M. F, Siqueira, E., \& Souza, V. F. de. (2002). Laranjeiras: construção de uma narrativa patrimonial com tecnologias digitais. VI Colóquio Internacional "Educação e contemporaneidade". 20 a 22 de setembro. São Cristovão, Sergipe.

Saga Entretenimento. Site Institucional. Recuperado de: https://sagaentretenimento.com.br/o-saga . [2017, 25 de janeiro].

Saari, T., Yoo, Y; Tussyadiah, I. (2008). Emotions in Mobile Media-Assisted Tourist Experience. Proceedings of the 58th Annual ICA Conference, 1-26. Montreal, Canada.

Thiesen, J. da S. (2010). Mediação tecnológica/pedagógica: diferentes perspectivas sobre um mesmo conceito. Congresso Iberoamericano de Educación. Metas 2021. Buenos Aires, República Argentina. 13, 14 y 15 de septiembre.

Tussyadiah, I. P; Fesenmaier, D. R. (2009). Mediating Tourist Experiences: Access to Places via Shared Videos. Annals of Tourism Research, 36 (1), 24-40.

Veal, A. (2011). Metodología de pesquisa em lazer e turismo. São Paulo: Aleph.

Viana, J. de A. (2010). Lazer e tecnologias da informação e comunicação (TICs): desafios para pensar a animação cultural na rede - um estudo da comunidade estudiolivre.org. (Dissertação de Mestrado). Universidade Federal de Minas Gerais, Belo Horizonte.

Wang, D., Park, S; Fesenmaier, D. R. (2011). The Role of Smartphones in Mediating the Touristic Experience. Journal of Travel Research, 51(4), 371-387.

\footnotetext{
' Citação no original: Obviamente, las variadas manifestaciones culturales son posibles de transformación y son influenciadas por distintas sociedades y culturas, especialmente en un mundo globalizado. Por esto, el ocio no se refiere solamente a las prácticas llamadas tradicionales o folclóricas, sino también a todo tipo de práctica social generalmente considerada como moderna y emergente. Entre ellas, por ejemplo, pueden ser citadas las experiências ligadas a la virtualidad, los nuevos gustos musicales, estilos de fiestas o determinadas actividades que para una persona de otra generación o de otra cultura pueden no ser comprendidos (Gomes, 2014b, p. 364-365).

ii SAGA é um evento realizado em Natal, no mês de abril, desde 2005, relacionando games, lazer e diversão. O objetivo do evento é divulgar iniciativas locais que visem à promoção de outras culturas, como adição a um leque cultural diverso e
} 
multifacetado. Fortalecendo as manifestações culturais produzidas no estado do Rio Grande do Norte, assim como difundindo seu acesso ao público. Além disso, pretende fomentar a pluralidade cultural, assim como fornecer uma alternativa de entretenimento voltada para toda a família. $O$ evento apresenta os expoentes potiguares, ajudando a divulgar a produção cultural local em um cenário alternativo e estimulante (SAGA Entretenimento, 2017).

\section{Recebido:29/07/2019-Aprovado em:27/08/2019}

